\title{
In-depth investigation of turn-around time of full blood count tests requested from a clinical haematology outpatient department in Cape Town, South Africa
}

\begin{tabular}{|c|c|}
\hline \multicolumn{2}{|c|}{$\begin{array}{l}\text { Authors: } \\
\text { Leonard Mutema }^{1,2} \text { (D) } \\
\text { Zivanai Chapanduka }^{1} \text { (D) } \\
\text { Fungai Musaigwa }^{1} \text { (D) } \\
\text { Nomusa Mashigo }^{1} \text { (D) }\end{array}$} \\
\hline \multicolumn{2}{|c|}{$\begin{array}{l}\text { Affiliations: } \\
{ }^{1} \text { Department of } \\
\text { Haematological Pathology, } \\
\text { Tygerberg Hospital, National } \\
\text { Health Laboratory Service and } \\
\text { Stellenbosch University, } \\
\text { Cape Town, South Africa }\end{array}$} \\
\hline \multicolumn{2}{|c|}{$\begin{array}{l}{ }^{2} \text { Department of Internal } \\
\text { Medicine, University of } \\
\text { KwaZulu-Natal, Durban, } \\
\text { South Africa }\end{array}$} \\
\hline \multicolumn{2}{|c|}{$\begin{array}{l}\text { Corresponding author: } \\
\text { Leonard Mutema, } \\
\text { Ipmutemah88@gmail.com }\end{array}$} \\
\hline \multicolumn{2}{|c|}{$\begin{array}{l}\text { Dates: } \\
\text { Received: } 27 \text { June } 2020 \\
\text { Accepted: } 06 \text { Jan. } 2021 \\
\text { Published: } 29 \text { Apr. } 2021\end{array}$} \\
\hline \multicolumn{2}{|c|}{$\begin{array}{l}\text { How to cite this article: } \\
\text { Mutema L, Chapanduka Z, } \\
\text { Musaigwa F, Mashigo N. } \\
\text { In-depth investigation of } \\
\text { turn-around time of full } \\
\text { blood count tests requested } \\
\text { from a clinical haematology } \\
\text { outpatient department in } \\
\text { Cape Town, South Africa. Afr J } \\
\text { Lab Med. 2021;10(1), a1318. } \\
\text { https://doi.org/10.4102/ajlm. } \\
\text { v10i1.1318 }\end{array}$} \\
\hline \multicolumn{2}{|c|}{$\begin{array}{l}\text { Copyright: } \\
\text { (C) 2021. The Authors } \\
\text { Licensee: AOSIS. This } \\
\text { is licensed under the } \\
\text { Creative Commons } \\
\text { Attribution License. }\end{array}$} \\
\hline \multicolumn{2}{|l|}{ Read online: } \\
\hline 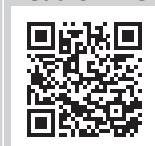 & $\begin{array}{l}\text { Scan this } Q R \\
\text { code with your } \\
\text { smart phone or } \\
\text { mobile device } \\
\text { to read online. }\end{array}$ \\
\hline
\end{tabular}

Background: The performance of laboratories can be objectively assessed using the overall turn-around time (TAT). However, TAT is defined differently by the laboratory and clinicians; therefore, it is important to determine the contribution of all the different components making up the laboratory test cycle.

Objective: We carried out a retrospective analysis of the TAT of full blood count tests requested from the haematology outpatient department at Tygerberg Academic Hospital in Cape Town, South Africa, with an aim to assess laboratory performance and to identify critical steps influencing TAT.

Methods: A retrospective audit was carried out, focused on the full blood count tests from the haematology outpatient department within a period of 3 months between 01 February and 30 April 2018. Data was extracted from the National Health Laboratory Service laboratory information system. The time intervals of all the phases of the test cycle were determined and total TAT and within-laboratory (intra-lab) TAT were calculated.

Results: A total of 1176 tests were analysed. The total TAT median was 275 (interquartile range [IQR] 200.0-1537.7) min with the most prolonged phase being from authorisation to review by clinicians (median $114 \mathrm{~min}$; IQR: 37.0-1338.5 min). The median intra-lab TAT was 55 (IQR 40-81) $\mathrm{min}$ and $90 \%$ of the samples were processed in the laboratory within $134 \mathrm{~min}$ of registration.

Conclusion: Our findings showed that the intra-lab TAT was within the set internal benchmark of $3 \mathrm{~h}$. Operational phases that were independent of the laboratory processes contributed the most to total TAT.

Keywords: audit; turn-around time; full blood count; haematology clinic.

\section{Introduction}

The increase in the number of patients accessing the public health system and the disproportionate patient to healthcare provider ratio in developing countries necessitates more efficient and costeffective approaches to healthcare provision..$^{1,2}$ The efficiency of healthcare providers is evaluated in part by how rapidly diagnoses are made and patients are prioritised for treatment. ${ }^{3}$ In addition, the rate at which laboratory results are made accessible to clinicians impacts both the patient outcome and the overall performance of a diagnostic laboratory. ${ }^{4}$ A prolonged turn-around time (TAT) results in delayed diagnosis and impacts the management of patients. This may lead to prolonged hospital stay and increased costs. ${ }^{5,6}$ The consequences of prolonged TAT are more pronounced in an emergency service setting and in outpatient departments, where a narrow window of opportunity exists to make key management decisions. ${ }^{7}$ Therefore, constant monitoring and improvement of the TAT in this setting is important to ensure the efficiency of laboratory services. ${ }^{8}$

The TAT is crucial in clinical practice and is used as a measure of the performance of laboratories. ${ }^{5}$ However, the TAT definition often varies between laboratories and clinicians, often resulting in unrealistic expectations. ${ }^{5,6,9,10}$ Total TAT is categorised into preanalytical, analytical and postanalytical stages and some define it as time from collection of the sample to when results are available for review by clinicians. ${ }^{9}$

Clinicians tend to view TAT as the time between requisition of a test and when they view a result. ${ }^{11}$ Laboratories are inclined to exclude components of the test cycle that they have no control over, 
such as phlebotomy and specimen transport ${ }^{12,13}$ because it is difficult for laboratories to address delays in these phases. ${ }^{5}$ Therefore, in laboratories, the TAT is usually defined as a measure of the time taken from sample registration to authorisation of results, also known as intra-lab TAT. ${ }^{5}$ Although this approach is not all inclusive of the phases of total TAT, it is generally accepted as the best representation of those elements of TAT that the laboratory controls. ${ }^{12}$

To assess the hypothesis that our laboratory performance was within set local benchmarks and comparable with the widely accepted international benchmark of completion of $90 \%$ of the sample processing within $60 \mathrm{~min}$, we performed a retrospective analysis to evaluate the respective contribution of the various phases of the test cycle to the total TAT at Tygerberg Academic Hospital (TBH) in Cape Town, South Africa. $^{14}$

\section{Methods \\ Ethical considerations}

This retrospective study was approved by the Stellenbosch University Research Ethics Committee (S18/10/232) and performed according to the Declaration of Helsinki. A waiver of consent was obtained, and patient confidentiality was maintained. Moreover, patient-level data was not accessed.

\section{Study design and setting}

A retrospective audit was conducted over a 3-month period between 01 February and 30 April 2018 at the haematological pathology laboratory of the tertiary referral $\mathrm{TBH}$ in Cape Town, South Africa. The laboratory and its reception operate on a 24-h service and have three shifts: regular shift (08:00 to $16: 30)$, evening shift (16:30 to 20:00) and night shift (20:00 to $08: 00)$.

The laboratory provides diagnostic pathology services to regional hospitals and clinics in the Western Cape, South Africa. At TBH laboratory reception, samples go through the processes of sorting, registration and labelling before being transported to the haematology laboratory for analysis where samples are loaded into a Siemens ADVIA 2120i haematology analyser (Siemens Healthcare Diagnostics, Erlangen, Germany). This analyser has the capacity of performing 120 full blood counts (FBCs) and differentials per hour. From the haematology analyser the preliminary results are entered into the laboratory information system (LIS) at which point the results are available to clinicians as provisional results. The laboratory fast-tracks all urgent samples and aims to release the results within $3 \mathrm{~h}$. Samples from the haematology clinic are treated as urgent and are colour coded and given preference over other routine samples. The LIS (InterSystems TrakCare ${ }^{\circledR}$ Lab Enterprise, Cambridge, Massachusetts, United States) tracks the processing of samples at various time points (preanalytical, analytical, and post-analytical).
The haematology clinic is housed in a separate building from the main building that houses the haematology laboratory. At this clinic, tests are requested through paper forms which are then placed alongside the samples into transporting bags and transported to the laboratory reception by porters or, rarely, by doctors or nurses. The clinic operates Monday to Friday from 07:00 to 16:00. Clinicians start seeing patients at 08:00 and most of the patient consultations are usually complete by 14:00, after which time the clinicians leave for the ward. Patients who arrive late are seen by one clinician until 16:00 when the clinic closes.

\section{Data collection}

We retrieved and extracted data from the LIS to determine the TAT reflecting all the operational phases. Reports with two or more missing entries of the date or time points on the LIS were excluded. Full blood counts done as part of bone marrow examination requests were also excluded as they are not reported separately but as part of the full bone marrow report. Four main phases of the test cycles were identified and evaluated. The first phase is between collection of samples (phlebotomy) and registration of the same in the laboratory. This is followed by the phase between registration of samples, processing by the haematology analyser, and loading of preliminary results into the LIS. The third phase is when preliminary results are reviewed by laboratory staff and then authorised, and the final phase is from authorisation of results to when clinicians view these results. In this study, the total TAT was defined as the time taken from specimen collection to the review of the results by the requesting clinician, while the intra-laboratory TAT was defined as the time taken from specimen registration to authorisation of results after review of preliminary results by the laboratory staff. Total TAT was therefore calculated, for each sample, by adding the time taken in the four phases which are: collection to registration, registration to acquisition into LIS, acquisition into LIS to authorisation and, finally, authorisation to review by clinicians. Intra-lab TAT was calculated by adding the time taken in the two phases which are: registration to acquisition into LIS and acquisition into LIS to authorisation of results. We also carried out a sub-analysis of samples collected in the month of April. The operation phase from the collection of samples to registration was divided into two phases: transportation time (collection to receipt in the laboratory) and sorting time (from receipt in the laboratory to registration of samples). The relative contribution of these two phases were determined and compared to that of a similar study. ${ }^{12}$

\section{Statistical analysis}

Data items which included sample collection, registration, acquisition to LIS, authorisation and review by clinicians were extracted from the LIS onto Microsoft ${ }^{\circledR}$ Office Excel (Redmond, Washington, United States) 2016 (version 16.0). Assessment of normality was done using the KolmogorovSmirnov test at $p<0.05$ significance level. ${ }^{15}$ Descriptive statistics, including median, percentages and interquartile 
range (IQR) were used. Intra-lab and total TAT were expressed as median with IQR and time to complete $90 \%$ of tests (90\% completion time). ${ }^{16}$ All time intervals were calculated in minutes. The chi-square test was used to compare the expected total TAT with the observed total TAT and to compare the sorting time of our laboratory with that of a study carried out at New York Presbyterian Hospital ${ }^{12}$; values of $p<0.05$ were considered statistically significant. Using the percentage contribution of each phase for all 1176 samples, median percentages were calculated. The same was done for the intra-lab TAT for each of the 1176 samples. All data analyses were performed using Statistica Software version 8 (TIBCO Software Inc., Palo Alto, California, United States).

\section{Results}

A total of 1505 FBCs were requested between 01 February and 30 April 2018 from the haematology clinic, TBH, Cape Town. We performed an analysis on a subset of the retrieved FBC reports over the study period. A total of 329 (22\%) patient reports were excluded either due to missing data (2 or more missing data points) or being reports for FBCs requested as part of a bone marrow biopsy (Figure 1). In all, this retrospective study included a total of 1176 FBC reports. Delays in registration of samples after receipt by the laboratory would not be reflected on the intra-laboratory TAT but on the total TAT. Therefore, a sub-analysis of the phase between collection and registration was performed for the month of April 2018. This comprised 412 samples for the phase between collection of samples to receipt in the laboratory and 420 samples for the phase from receipt to registration. Seventy percent of the 1176 samples were collected by $9: 00$ and $90 \%$ by 11.00 . Considering the closing time of the clinic, the clinicians had a window of $7 \mathrm{~h}$ and $5 \mathrm{~h}$ to receive results and make clinical decisions for $70 \%$ and $90 \%$ of patients.

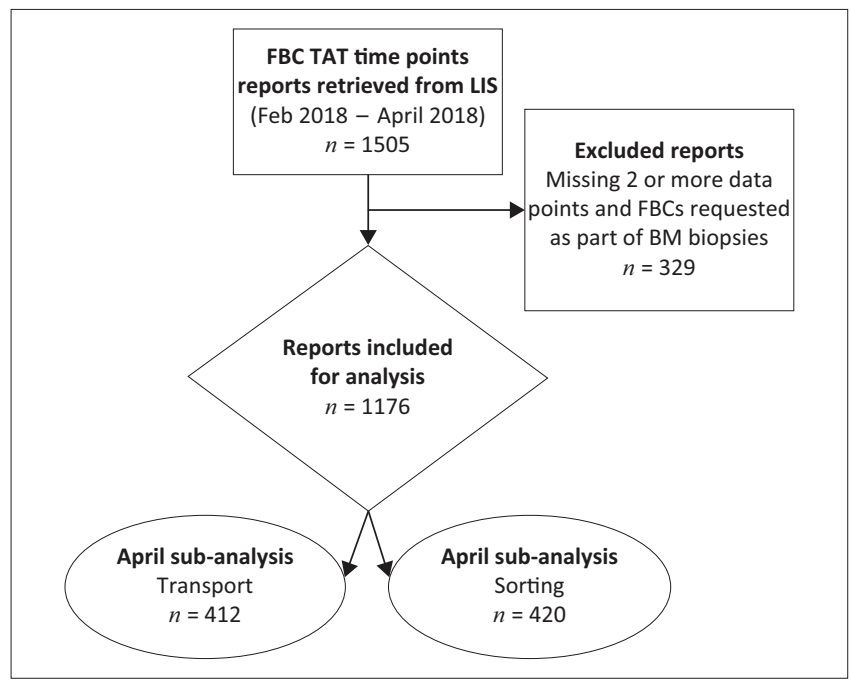

TAT, turn-around time; LIS, laboratory information system; BM, bone marrow; FBC, full blood count.

FIGURE 1: Screening and selection of reports of full blood counts requested from the haematology outpatient department at Tygerberg Academic Hospital in Cape Town, South Africa, over the period February 2018 to April 2018.

\section{Intra-laboratory turn-around time and total turn-around time}

The majority of the FBC samples (93.3\%) had an intra-lab TAT of less than $3 \mathrm{~h}$ and most of them $(80.1 \%)$ were processed within 90 min (Table 1). The median intra-lab TAT was 55 (IQR 40-81) $\mathrm{min}$ and had a median percentage of $17.1 \%$ of the total TAT (Table 2). Ninety percent of the results were ready for viewing by clinicians within $134 \mathrm{~min}$ of registration. The median total TAT was 275 (IQR 200.0-1537.7) min. The phases within the preanalytical and post-analytical phases contribute the most to the total TAT, with collection time to registration and time to review results by clinicians representing a median of $32.5 \%$ (IQR 7.8-48.7) and $44.3 \%$ (IQR 18.1-87.0). The total TAT was significantly delayed compared to the calculated expected TAT $(p<0.05)$.

\section{Preanalytical phase}

The preanalytical phase, defined in this study as the time from collection of samples to registration, had a median of 96 min (Table 2). Ninety percent of the samples completed this phase within $218 \mathrm{~min}$. A sub-analysis of this phase during the month of April revealed a median of 60 (IQR 45-85) min for the period between collection of the sample to receipt in the laboratory (transportation) and a median of 39 (IQR 23.35-58.00) $\mathrm{min}$ from receipt to registration (sorting) (Table 3). Most of the samples (90\%) spent less than $95 \mathrm{~min}$ in the sorting area. Our laboratory performed significantly worse when we compared the time spent in the sorting area for each sample in April with the median of $15 \mathrm{~min}$ at New York Presbyterian Hospital, another tertiary hospital described in literature, using the chi-square test. ${ }^{12}$

\section{Analytical phases}

We categorised the analytical phase into two independent intervals (interval 2 and interval 3) (Table 1). Our analysis showed that most samples $(73.3 \%)$ spent less than $60 \mathrm{~min}$ in interval 2 while $85.2 \%$ of samples were authorised within $30 \mathrm{~min}$ in interval 3. Notably, a few samples, $26.6 \%$ and $6.3 \%$, took more than $1 \mathrm{~h}$ in interval 2 and interval 3 . The authorisation of reports is also impacted by the battery of laboratory tests requested and this may explain the minority of samples authorised after an hour.

\section{Post-analytical phase}

We further evaluated the time taken by clinicians to review the authorised reports (interval 4). We observed a significant number of reports $(48.9 \%)$ that were accessed after $2 \mathrm{~h}$, while only $22.7 \%$ of the reports were viewed within $30 \mathrm{~min}$ (Table 1 ). Notably, $38.6 \%$ of reports were viewed after $4 \mathrm{~h}$. The median time for this phase was 114 (IQR 37.0-1338.5) $\mathrm{min}$ and the time to view $90 \%$ of the reports was 10.78 days (Table 2 ).

\section{Discussion}

The constant increase in medical care cost and the growing demand for improved quality of care has necessitated the 
TABLE 1: Contribution of the different phases of sample processing to total turn-around time and intra-lab turn-around time.

\begin{tabular}{|c|c|c|c|c|c|c|c|c|c|c|}
\hline \multirow[t]{2}{*}{$\begin{array}{l}\text { Time taken } \\
\text { (min) }\end{array}$} & \multirow{2}{*}{\multicolumn{2}{|c|}{$\begin{array}{c}\text { Preanalytical phase } \\
(n=1176) \\
\text { Collection to registration } \\
\text { (Interval 1) }\end{array}$}} & \multicolumn{4}{|c|}{$\begin{array}{l}\text { Analytical phase } \\
(n=1176)\end{array}$} & \multirow{2}{*}{\multicolumn{2}{|c|}{$\begin{array}{l}\text { Post-analytical phase } \\
(n=1176) \\
\text { Authorisation to review by } \\
\text { clinicians (Interval 4) }\end{array}$}} & \multirow{2}{*}{\multicolumn{2}{|c|}{$\begin{array}{l}\text { Intra-laboratory } \\
\text { turn-around time } \\
\quad(n=1176)\end{array}$}} \\
\hline & & & \multicolumn{2}{|c|}{$\begin{array}{l}\text { Registration to LIS acquisition } \\
\text { (Interval 2) }\end{array}$} & \multicolumn{2}{|c|}{$\begin{array}{l}\text { LIS acquisition to authorisation } \\
\text { (Interval 3) }\end{array}$} & & & & \\
\hline$<30$ & 64 & 5.4 & 227 & 19.3 & 1002 & 85.2 & 267 & 22.7 & 108 & 9.2 \\
\hline $30-59$ & 114 & 9.7 & 635 & 54.0 & 100 & 8.5 & 131 & 11.1 & 551 & 46.9 \\
\hline $60-89$ & 354 & 30.1 & 198 & 16.8 & 37 & 3.1 & 122 & 10.4 & 283 & 24.1 \\
\hline $120-149$ & 167 & 14.2 & 7 & 0.6 & 9 & 0.8 & 57 & 4.8 & 34 & 2.9 \\
\hline 150-179 & 49 & 4.2 & 8 & 0.7 & 2 & 0.2 & 29 & 2.5 & 21 & 1.8 \\
\hline 180-209 & 29 & 2.5 & 8 & 0.7 & 4 & 0.3 & 20 & 1.7 & 13 & 1.1 \\
\hline $210-240$ & 26 & 2.2 & 5 & 0.4 & 2 & 0.2 & 15 & 1.3 & 4 & 0.3 \\
\hline$>240$ & 101 & 8.6 & 41 & 3.5 & 9 & 0.8 & 454 & 38.6 & 63 & 5.4 \\
\hline
\end{tabular}

Note: The times were retrieved from the National Health Laboratory Services laboratory information system at Tygerberg Academic Hospital in Cape Town, South Africa, for the period February 2018 to April 2018

LIS, laboratory information system.

TABLE 2: Summary of turn-around times across phases of workflow for 1176 full blood count requests from the haematology outpatient department at Tygerberg Academic Hospital in Cape Town, South Africa, over the period February 2018 to April 2018.

\begin{tabular}{|c|c|c|c|c|c|c|}
\hline Parameter & $\begin{array}{l}\text { Collection to } \\
\text { registration }\end{array}$ & $\begin{array}{c}\text { Registration to LIS } \\
\text { acquisition }\end{array}$ & $\begin{array}{l}\text { LIS acquisition to } \\
\text { authorisation }\end{array}$ & $\begin{array}{c}\text { Authorisation to review of } \\
\text { results }\end{array}$ & Intra-laboratory TAT & Total TAT \\
\hline Median (minutes) & 96 & 44 & 7 & 114 & 55 & 275 \\
\hline Median $\%$ of total TAT (\%) & 32.5 & 13.6 & 1.3 & 44.3 & 17.1 & - \\
\hline Interquartile range (minutes) & $73-133$ & $33-62$ & $2.0-19.0$ & $37-1338.5$ & $40-81$ & $200-1537.7$ \\
\hline $90 \%$ completion time (minutes) & 218 & 90 & 41 & 15530 & 134 & 15773 \\
\hline
\end{tabular}

LIS, laboratory information system; TAT, turn-around time.

TABLE 3: Summary of phases between collection to registration of full blood count samples at the haematology outpatient department for the month of April 2018 at Tygerberg Academic Hospital in Cape Town, South Africa.

\begin{tabular}{lcc}
\hline Parameter & $\begin{array}{c}\text { Collection to receipt at } \\
\text { laboratory }\end{array}$ & $\begin{array}{c}\text { Receipt at laboratory to } \\
\text { registration }\end{array}$ \\
\hline Number of samples & 412 & 420 \\
Median (minutes) & 60 & 39 \\
Interquartile range & $45-85$ & $23-58$ \\
$90 \%$ completion time (minutes) & 136 & 95 \\
\hline
\end{tabular}

monitoring of determinants of the quality of healthcare services. ${ }^{17,18}$ The TAT is one of the determinants that is commonly measured, as it is both objective and easily measured. ${ }^{19}$ However, different views exist regarding the definition of what the composition of the TAT should be. These are often compounded by the lack of an interface for dialogue between the laboratory staff and clinicians. Howanitz et al. showed that there was also no agreement among clinicians as to the definition of TAT, with 56\% using test requisition as the first step of TAT, while $44 \%$ used the time of phlebotomy as the initial step. Although most studies use reporting of results as the endpoint of TAT, ${ }^{17}$ this study defined total TAT as the time period from the time of phlebotomy to the time the results are reviewed by clinicians, whereas we considered the intra-laboratory TAT as the time from registration of the sample to reporting of results (authorisation). This was done in efforts to determine the relative contribution of different phases of the laboratory process to TAT and to identify phases requiring the most attention in alleviating delays. This study showed that the phases outside of the laboratory environment needed the most attention and that the laboratory was meeting its predetermined mandate.
Samples from the haematology outpatient department at $\mathrm{TBH}$ are regarded as urgent because for most patients, FBCs are required to make decisions on chemotherapy, transfusion and other interventions before leaving the clinic. The results of this study were therefore compared to findings of studies on TAT of emergency departments. Our findings were similar to those previously reported. ${ }^{5,20}$ The preanalytical and post-analytical phases accounted for a greater proportion of the total TAT, with a median of 60 min transportation time (preanalytical phase) and $48.9 \%$ of the post-analytical phase taking more than $120 \mathrm{~min}$. In contrast, most of the samples were processed in the laboratory within $90 \mathrm{~min}$. The median intra-lab TAT was 55 (IQR 40-81) $\mathrm{min}$ and $90 \%$ of samples were authorised within $134 \mathrm{~min}$. Therefore, our findings suggest that the laboratory is performing within the set threshold of $3 \mathrm{~h}$ as stated by the TBH laboratory standard operating procedure HAE1813 for tests from the haematology clinic. This highlights the need to further interrogate the phases that the laboratory has no control over, that is, the preanalytical and post-analytical phases.

In addition to the lack of consensus on the definition of TAT, there is also no specific benchmark for TAT parameters. ${ }^{21}$ However, databases used to benchmark TAT thresholds can be obtained from the College of American Pathologists Q-Probes and Q-Tracks programmes. ${ }^{16}$ We therefore used these databases and experiences from other international hospitals to assess our performance. The 1998 College of American Pathologists Q-Probes study of emergency department TATs showed a 90\% completion time for haemoglobin testing of $55 \mathrm{~min}$ or less. ${ }^{22}$ In this study $90 \%$ completion time of $60 \mathrm{~min}$ or less is recommended, ${ }^{22}$ as 
opposed to that of TBH which is $134 \mathrm{~min}$. In a survey carried out in Nigeria involving 109 doctors, $91.3 \%$ of the respondents considered a TAT of less than $2 \mathrm{~h}$ as ideal for their laboratory, although their median TAT in emergency rooms was $5.12 \mathrm{~h}^{23}$ In a Chinese national survey the median intra-lab TAT for white blood cells was $44.7 \mathrm{~min} .{ }^{24}$ Although our laboratory performance was within the local threshold, our laboratory performed below the expectations when compared to other laboratories in a similar setting. 5,7,23,24 The April sub-analysis exposed the sorting area as a problematic area that is responsible for prolongation of the intra-lab TAT and ultimately total TAT. Few studies focus on the analysis of this phase as the time of receipt of samples in the laboratory is often missing; therefore, the study at New York Presbyterian Hospital, which analysed total TAT with emphasis on quantification of sorting time, was best suited for comparison with this study. ${ }^{12}$ As with this study, sorting time was also prolonged at New York Presbyterian Hospital. Opening of sample bags, generation and printing of barcodes and decoding handwritten requests were responsible for the delays in the sorting area, which is also partly the case at TBH. ${ }^{12}$ Electronic requesting of tests as well as the generation of barcodes at the time of requesting tests were suggested as solutions to this delay. ${ }^{12}$

Total TAT was significantly prolonged compared to the expected TAT, with phases outside the laboratory causing the most delay. The time taken to view results by clinicians was the longest with a median time of 114 (IQR 37.0-1338.5) min. This could be due to the limited period during which clinicians can view results. Once this window has elapsed the results can only be viewed on the patient's next appointment which can vary from a day to several months later. This is a limitation of total TAT in assessing laboratory performance, which explains in part why laboratories resort to the use of intra-lab TAT. ${ }^{12}$ These delays can be improved by ensuring patients' punctuality and having the laboratory contact the clinicians with results as soon as they are authorised. The other cause of delay for total TAT was the time taken to transport samples from the clinic to the laboratory as well as sorting time. Porters tend to wait for samples to pile up before transporting them. Having a set time for phlebotomy and ensuring that patients avail themselves at this time may mitigate this problem. In addition, the use of pneumatic tube systems results in faster and reliable transportation of samples..$^{25,26}$

As it is noted that a pragmatic approach is to set TAT goals locally, informed by both the published literature and by local expectations, ${ }^{5}$ we made the following recommendations: establishment of point-of-care testing at the haematology clinic, employment of additional staff for the sorting area or the use of an automated barcode system, and the use of pneumatic tube systems. We also recommend the use of an interactive TAT dashboard, a recently described system that offers information to enable the review of performance in real time. ${ }^{27}$ This may help in ensuring timely response to changes in performance. However, solutions requiring extra funding may take time to implement due to economic challenges facing the health sector in South Africa. ${ }^{2,28}$ As noted earlier, some results are only reviewed on the patient's next visit and this may pose serious challenges to patient care. Therefore, the use of other communication avenues such as short message services, WhatsApp, or emails to send authorised results to clinicians is recommended. Not only will this improve the total TAT, but it will also allow clinicians to act on results immediately rather than waiting for the patient's next appointment. Another suggestion is for clinicians to employ a clerk to review results even after the clinicians have left the clinic. For the laboratory, we recommend that considerations be made to incorporate phlebotomy and specimen transportation services into its armamentarium of service delivery. This will increase laboratory influence on preanalytical processes and subsequently improve total TAT.

\section{Limitations}

This study was limited by the absence of an interventional process, and we therefore recommend a follow-up audit after implementing some of the proposed solutions. The results from this study cannot be extrapolated to all hospitals and departments but only to those with a similar setting, as they are solely based on the experience of the haematology clinic at TBH. The collection times were based on what was reported by the nurses at the clinic; therefore, the accuracy of the recorded time following each phlebotomy cannot be ascertained. This is not the case for other time points retrieved from the LIS as they are computer generated in real time. In addition, the laboratory receipt time for samples was not available for the entire study period. As noted earlier, $22 \%$ of the data had 2 or more missing data points which were critical in the calculation of intra-lab TAT and total TAT. This has the potential of introducing bias, which is likely if the proportion of missing data is greater than $10 \%{ }^{29}$ These missing data points were random occurrences on the extracted LIS data and TATs could not be computed; therefore, the samples were removed in a non-biased manner by listwise deletion. Due to the random nature of these missing points, a case is therefore made that the generalisability of the study is not affected. The statistical method of handling missing data used in this case was complete-case analysis, which only includes participants or variables that are complete on all waves of data collection. ${ }^{30}$

\section{Conclusion}

This study demonstrated that TBH laboratory was compliant with its intra-lab TAT benchmark and that the $90 \%$ completion time target was achieved for samples from the haematology outpatient clinic. The phases outside the control of the laboratory were primarily responsible for prolonged total TATs. The monitoring of TAT is a powerful tool for assessing a laboratory service's performance and contributes to patient care. However, as demonstrated in this study, monitoring and process improvement requires measurement of TATs for individual phases of the test cycle. 


\section{Acknowledgements}

The authors would like to thank Ms Fazlin Kolia, the laboratory manager, for providing us with permission to use LIS data and standard operation procedures. We also would like to extend our gratitude to Mr Wessel Kleinhans for his critical role in data mining from the LIS. Lastly, we would like to thank Prof. Bongani Nkambule for assistance in analysis of the data.

\section{Competing interests}

The authors declare that they have no financial or personal relationships that may have inappropriately influenced them in writing this article.

\section{Authors' contributions}

N.M. and Z.C. supervised the study by providing leadership and oversight. L.M. conceptualised the study, conducted the research and wrote the initial manuscript. F.M. and L.M. conducted data analysis. All authors contributed to final manuscript development.

\section{Sources of support}

The authors received no financial support for the research, authorship or publication of this article.

\section{Data availability}

The data that support the findings of this study are available from the corresponding author, L.M., upon reasonable request.

\section{Disclaimer}

The views and opinions expressed in this article are those of the authors and do not necessarily reflect the official policy or position of any affiliated agency of the authors.

\section{References}

1. Veld M, Van De Voorde K. How to take care of nurses in your organization: Two types of exchange relationships compared. J Adv Nurs. 2013;70(4):855-865. https://doi.org/10.1111/jan.12247

2. Van Rensburg H. South Africa's protracted struggle for equal distribution and equitable access - Still not there. 2014;12(26):1-16. https://doi.org/10.1186/ 1478-4491-12-26

3. Mishra V. Measuring technical efficiency in healthcare service: A case study Pacific Bus Rev Int. 2019;11(6):36-43.

4. Valenstein P. Laboratory turnaround time. Am J Clin Pathol. 1996;105(6):676-688. https://doi.org/10.1093/ajcp/105.6.676

5. Hawkins RC. Laboratory turnaround time. Clin Biochem Rev. 2007;28(4):179-194.

6. Jalili M, Shalileh K, Mojtahed M, Moradi-Lakesh M. Identifying causes of laboratory turnaround time delay in the emergency department. Arch Iran Med. 2012; 15(12):759-763.
7. Kaushik N, Khangulov VS, O'Hara M, Arnaout R. Reduction in laboratory turnaround time decreases emergency room length of stay. Open Access Emerg Med. 2018;10:37-45. https://doi.org/10.2147/OAEM.S155988

8. Imoh LC, Mutale M, Parker CT, Erasmus RT, Zemlin AE. Laboratory-based clinical audit as a tool for continual improvement: An example from CSF chemistry turnaround time audit in a South-African teaching hospital. Biochem Medica. 2016;26(2):194-201. https://doi.org/10.11613/BM.2016.021

9. Schimke I. Quality and timeliness in medical laboratory testing. Anal Bioana Chem. 2009;393(5):1499-1504. https://doi.org/10.1007/s00216-008-2349-5

10. Groenewald AJ, Potgieter HD. Physician satisfaction and emergency (stat) laboratory turnaround time during various developmental stages. Med Techno SA. 2014;28(1):20-25.

11. Weinstein S. Quality in pathology laboratory practice. J Qual Clin Pr 1995;15(2):121-126.

12. Stotler BA, Kratz A. Determination of turnaround time in the clinical laboratory. Am J Clin Pathol. 2012;138(5):724-729. https://doi.org/10.1309/ AJCPYHBT9OQRM8DX

13. Chung HJ, Lee W, Chun S, Park H-I, Min WK. Analysis of turnaround time by subdividing three phases for outpatient chemistry specimens. Ann Clin Lab Sci. 2009;39(2):144-149.

14. Howanitz PJ. Errors in laboratory medicine: Practical lessons to improve patient safety. Arch Pathol Lab Med. 2005;129(10):1252-1261.

15. Mishra P, Pandey C, Singh U, Gupta A, Sahu C, Keshri A. Descriptive statistics and normality tests for statistical data. Ann Card Anaesth. 2019;22(1):67-72. https:// doi.org/10.4103/aca.ACA_157_18

16. Howanitz JH, Howanitz PJ. Timeliness as a quality attribute and strategy. Am J Clin Pathol. 2001;116(3):311-315. https://doi.org/10.1309/HODY-6VTW-NB36-U3L6

17. Howanitz P, Cembrowski G, Steindel SJ, Long T. Physician goals and laboratory test turnaround times. A college of American pathologists Q-probes study of 2763 clinicians and 722 institutions. Arch Pathol Lab Med. 1993;117(1):22-28.

18. Breil B, Fritz F, Thiemann V, Dugas M. Mapping turnaround times (TAT) to a generic timeline: A systematic review of TAT definitions in clinical domains. BMC Med Inform Decis Mak. 2011;11(34):1-12. https://doi.org/10.1186/1472-6947-11-34

19. Bloch DM. Computer-generated management tools for the clinical pathology laboratory - II. Computer-generated graphic work flow. J Med Syst. 1982;6(3):305310. https://doi.org/10.1007/BF00992807

20. Mahdaviazad H, Javidialesaadi F, Hosseinzadeh M, Masoompour SM. Turnaround times for hematology and chemistry tests in the emergency department: Experience of a teaching hospital in Iran. Shiraz E Med J. 2016;17(4-5):e37101. https://doi.org/10.17795/semj37101

21. Dey B, Bharti J, Chakraborty M. Laboratory turnaround time. Int J Heal Sci Res. 2013;3(5):82-84.

22. Steindel SJ, Howanitz PJ. Physician satisfaction and emergency department laboratory test turnaround time. Arch Pathol Lab Med. 2001;125(7):863-871.

23. Bolodeoku J, Ogbeiwi O, Kuti MA, Adebisi SA. Laboratory tests turnaround time in outpatient and emergency patients in Nigeria: Results of a physician survey on point of care testing. Int J Med Res Heal Sci. 2017;6(5):76-81.

24. Fei Y, Zeng R, Wang W, He F, Zhong K, Wang Z. National survey on intra-laboratory turnaround time for some most common routine and stat laboratory analyses in 479 laboratories in China. Biochem Medica. 2015;25(2):213-221. https://doi. org/10.11613/BM.2015.021

25. Fernandes C, Worster A, Eva K, Hill S, McCallum C. Pneumatic tube delivery system for blood samples reduces turnaround times without affecting sample quality. J Emerg Nurs. 2006;32(2):139-143. https://doi.org/10.1016/j.jen.2005.11.013

26. Guss $D$, Chan T, Killeen J. The impact of a pneumatic tube and computerized physician order management on laboratory turnaround time. Ann Emerg Med. 2008;51(2):181-185. https://doi.org/10.1016/j.annemergmed.2007.03.010

27. Cassim N, Coetzee LM, Tepper ME, Perelson L, Glencross DK. Timely delivery of laboratory efficiency information, part I: Developing an interactive turnaround time dashboard at a high-volume laboratory. Afr J Lab Med. 2020;9(2):a948. https://doi.org/10.4102/ajlm.v9i2.948

28. Malakoane B, Heunis JC, Chikobvu P, Kigozi NG, Kruger WH. Public health system challenges in the Free State, South Africa: A situation appraisal to inform health system strengthening. BMC Health Serv Res. 2020;20(1):1-14. https://doi. org/10.1186/s12913-019-4862-y

29. Bennett DA. How can I deal with missing data in my study? Aust N Z J Public Health 2001;25(5):464-469. https://doi.org/10.1111/j.1467-842X.2001.tb00294.x

30. Shortreed SM, Forbes AB. Missing data in the exposure of interest and margina structural models: A simulation study based on the Framingham Heart study. Stat Med. 2010;29(4):431-443. 